\title{
An Assessment of Antimicrobial Prescription Pattern among Surgical Patients: A Hospital Based Cross Sectional Descriptive Study
} Bikash Bahadur Rayamajhi', Sunil Basukala ${ }^{1}$, Anjan Khadka ${ }^{2}$, Narayan Thapa ${ }^{1}$, Dhirendra Bahadur Ayer $^{1}$

\section{Abstract}

\section{Introduction}

Antimicrobials are used before, during and after surgery to prevent infections to decrease the duration of hospital stay, increase surgical outcomes and reduce health-related costs. There is inadequate evidence to determine the effective group of antimicrobials to be used in surgical prophylaxis in our settings.

\section{Methods}

A hospital-based cross-sectional descriptive study involving antimicrobial prescriptions pattern among 223 surgical patients was undertaken. Information on patient's demographic variables, diagnosis, type of surgery and wound, perioperative antimicrobial use, postoperative complications and number of antimicrobials prescribed from the essential medicine list were recorded. The antibiotic prescription patterns were assessed based on a comparison with international and national guidelines.

\section{Results}

Among 223 patients, males were predominant with an overall mean age of 42.77 years. The total number of diagnoses was 30 , the commonest being appendicitis $(21.52 \%)$, urinary stone disease $(15.69 \%)$, hernia $(13.90 \%)$ and cholelithiasis (11.65\%). The common surgeries performed were emergency appendectomy, hernioplasty and laparoscopic cholecystectomy. Eighteen types of drugs from seven different antimicrobial groups were used perioperatively, out of which $73 \%$ and $83 \%$ were prescribed based on international and national guidelines respectively.

\section{Conclusion}

The most common antimicrobial used was third-generation cephalosporin. The postoperative antimicrobial rate was found higher compared to preoperative and intraoperative prescriptions and for a longer duration compared to national and international guidelines.

Keywords: Antimicrobials; Infection; Prescription; Surgical wound.

\section{Author affiliations:}

${ }^{1}$ Department of Surgery, Nepalese Army Institute of Health Sciences (NAIHS), Sanobharyang, Kathmandu, Nepal.

${ }^{2}$ Department of Pharmacology, Nepalese Army Institute of Health Sciences (NAIHS), Sanobharyang, Kathmandu, Nepal.

\section{Correspondence:}

Dr. Bikash Bahadur Rayamajhi, Assistant professor, Department of Surgery, Nepalese Army Institute of Health Sciences (NAIHS), Sanobharyang, Kathmandu, Nepal.

Email: drbikashrayamajhi@gmail.com

ORCID

https://orcid.org/0000-0001-8666-4761

Disclosures:

Ethical Clearance: IRB of NAIHS

Conflict of interest: None

Financial aid: None

Copyright information:

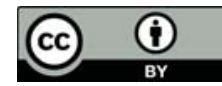

Authors retain copyright and grant the journal right of first publication with the work simultaneously licensed under Creative Commons Attribution License under CC-BY 4.0 that allows others to share the work with an acknowledgement of the works's authorship and initial publication of this journal.

\footnotetext{
How to cite this article:

Rayamajhi BB, Basukala S, Khadka A, Thapa N, Ayer DB. An assessment of antimicrobial prescription pattern among surgical patients a hospital based cross sectional descriptive study. J Soc Surg Nep. 2021 Jul; 24(1):23-7.

DOI:

https://doi.org/10.3126/jssn.v24i1.41004
} 


\section{Introduction}

Surgical operation refers to procedures performed by surgeons by using instruments to repair or reconstruct the damaged tissue, destroy or restore the integrity of tissues and/or to place an implant in a living body. ${ }^{1}$ The perioperative period relates to the time before, during and after surgical operation. Antimicrobial agents are widely used to prevent and treat infection in surgical operations during the perioperative period. ${ }^{2-4}$

Preoperative and intraoperative use of antimicrobials is intended for prophylactic purposes whereas postoperative use of antimicrobials is for a therapeutic purpose: to treat surgical site infection (SSI). ${ }^{5-7}$ The goals of antimicrobial administration to surgical inpatients focus on preventing SSI-related morbidity and mortality thereby reducing the economic burden on health care and minimizing the modification of patients' endogenous bacterial flora. ${ }^{8}$ Antimicrobials can be misused by inappropriate prescription in the form of unnecessary indications, wrong dose, variable duration, and not following the recommended guidelines and pharmacological principles. ${ }^{4}$

Though there is a common trend of administering antimicrobial perioperatively, it is still controversial to use such antimicrobials without definitive indications. ${ }^{9,10}$ There should be rational use of antimicrobials to prevent SSI and enhance the rate of wound healing. There are numerous studies on pre- and intraoperative use of antimicrobials in comparison to postoperative use. ${ }^{6,7}$ There is a need for studies that focus on the utilization of various antimicrobials perioperatively to provide a reference and evidence for rational use of antimicrobials. Hence, the study is planned to assess the prescription practices of antimicrobials perioperatively in the surgical department of a tertiary care hospital.

\section{Methods}

This was a hospital-based cross-sectional descriptive study involving 223 patients admitted and operated by the department of surgery of a tertiary care hospital of Central Nepal from 1st January 2019 to 31st March 2019. Approval of the institutional ethics committee was taken before the commencement of the study. The prescriptions of antimicrobials in the operated patients admitted under the department of surgery were included in the study. The prescriptions of patients who did not undergo surgical intervention and the prescriptions without the doctor's signature and diagnosis were excluded from the study. Information was recorded in a customized proforma. The patient's demographic variables (age, sex), diagnosis, type of surgery, type of surgical wound, type of antimicrobials used during perioperative were recorded. Similarly, the antibiotics prescribed for every individual patient were noted in detail (route, dose and duration) in the case record form followed up by analysis of the prescription pattern. The compliance of antibiotics prescribed with the type of surgery performed was compared based on international guidelines (Global guidelines for the prevention of surgical site infection by $\mathrm{WHO}^{11}$ ), hospital based antibiotic stewardship protocol and National antibiotic treatment guidelines developed by the ministry of health and population (MoHP) Nepal. ${ }^{12}$ Data was entered in the MSExcel and expressed as mean \pm standard deviation (SD). IBM SPSS version 20.0 was used for statistical analysis. A p-value $<0.05$ was considered statistically significant.

\section{Results}

The total number of prescriptions included in the study was 223. The maximum numbers of prescriptions 42 (18.88\%) were of patients from 51 to 60 years age group whereas the minimum numbers of prescriptions $12(5.3 \%)$ were from 11 to 20 years age group. The mean age of the patients was 42.77 years (3-78 years). The number of male and female patients involved in the study was $126(56.5 \%)$ and 97 (43.4\%) respectively with male to female ratio being $1.29: 1$. The mean length of hospital stay was $3.23 \pm 2.14$ days.

The total number of diagnoses was 30 , the commonest being appendicitis $(21.52 \%)$, urinary stone disease (15.69\%), hernia (13.90\%) and cholelithiasis (11.65\%). Our study showed 40 different types of surgeries for thirty types of diagnosis. The top five common surgeries were emergency appendectomy, hernioplasty, laparoscopic cholecystectomy, percutaneous nephrolithotomy (PCNL), and transurethral resection of prostate (TURP) (Table 1).

\section{Table 1. Top five surgeries performed in different} diagnoses

\begin{tabular}{|c|c|c|c|}
\hline $\begin{array}{l}\text { S. } \\
\text { No. }\end{array}$ & Diagnosis & $\begin{array}{l}\text { Type of surgery } \\
\text { Performed }\end{array}$ & $\begin{array}{l}\text { No. of } \\
\text { surgery } \\
n(\%)\end{array}$ \\
\hline 1. & Acute appendicitis & Appendectomy & $\begin{array}{l}48 \\
(21.52 \%)\end{array}$ \\
\hline 2. & $\begin{array}{l}\text { Urolithiasis } \\
\text { (Renal/Ureteric/ } \\
\text { Vesical) }\end{array}$ & $\begin{array}{l}\text { PCNL }^{*}-14 \\
\text { Nephrolithotomy- } 5 \\
\text { URSL** }-13 \\
\text { Ureterolithotomy - } 1 \\
\text { Cystolitholapaxy - } 1 \\
\text { Cystolithotomy - 1 }\end{array}$ & $\begin{array}{l}35 \\
(15.69 \%)\end{array}$ \\
\hline 3. & $\begin{array}{l}\text { Hernia } \\
\text { (Congenital/ } \\
\text { Inguinal/ Umbilical/ } \\
\text { Incisional) }\end{array}$ & $\begin{array}{l}\text { Hernioplasty - } 26 \\
\text { Herniotomy - } 5\end{array}$ & $\begin{array}{l}31 \\
(13.90 \%)\end{array}$ \\
\hline 4. & Cholelithiasis & $\begin{array}{l}\text { Laparoscopic -23 } \\
\text { Open - } 3\end{array}$ & $\begin{array}{l}26 \\
(11.65 \%)\end{array}$ \\
\hline 5. & $\begin{array}{l}\text { Benign anorectal } \\
\text { diseases } \\
\text { (Hemorrhoids / } \\
\text { Fistula in ano /Anal } \\
\text { Fissure) }\end{array}$ & $\begin{array}{l}\text { Hemorrhoidectomy }-8 \\
\text { LIFT }^{* * *} \text { - } 4 \\
\text { Fistulotomy- } 2 \\
\text { Sphincterotomy }-4\end{array}$ & $\begin{array}{l}18 \\
(8.07 \%)\end{array}$ \\
\hline
\end{tabular}

*PCNL- PCNL- Percutaneous Nephrolithotomy; **URSLUretreroscopic Lithotripsy; ***LIFT- Ligation of Intersphincteric Fistula 
Table 2. Top five antimicrobials used perioperatively

\begin{tabular}{|c|c|c|c|}
\hline $\begin{array}{l}\text { S. } \\
\text { No. }\end{array}$ & $\begin{array}{l}\text { Group of } \\
\text { antimicrobials }\end{array}$ & Drugs & Type of surgery \\
\hline \multirow[t]{5}{*}{1.} & \multirow[t]{5}{*}{ Cephalosporins } & Ceftriaxone & $\begin{array}{l}\text { Appendicitis, Cholecystectomy, Hernioplasty, Herniotomy, Hemicolectomy, } \\
\text { Ileostomy Closure, PCNL/ Nephrolithotomy, URLS/Ureterolithotomy, } \\
\text { Cystolitholapaxy, TURP/ Orchidopexy/Varicocelectomy }\end{array}$ \\
\hline & & Cefazolin & Cholecystectomy \\
\hline & & Cefuroxime & Hemicolectomy \\
\hline & & Cefotaxime & RPP \\
\hline & & Cefexime & $\begin{array}{l}\text { Appendectomy, Cholecystectomy, Gastrectomy, Esophagotomy, } \\
\text { Hemicolectomy, Exploratory laparotomy, Ileostomy Closure, Resection and } \\
\text { Anastomosis, TURP/ RPP, Orchidopexy/ Varicocelectomy, Circumcision, } \\
\text { MRM, Trendelenberg's Procedure, Skin Grafting, Lump Excision, Wide } \\
\text { Local Excision }\end{array}$ \\
\hline 2. & Carbapenems & Imipenem + Cilastatin & Gastrectomy, Altemeier's Repair \\
\hline \multirow[t]{3}{*}{3.} & \multirow[t]{3}{*}{ Fluoroquinolones } & Ciprofloxacin & $\begin{array}{l}\text { Appendectomy, Hemorrhoidectomy/ LIFT/ Sphincterotomy, Karydaky's } \\
\text { Procedure, Altemeier's Repair, PCNL/ Nephrolithotomy, URLS/ } \\
\text { Ureterolithotomy, Cystolitholapaxy, TURP/ RPP, Prostatic Biopsy }\end{array}$ \\
\hline & & Ofloxacin & PCNL/ Nephrolithotomy, URLS/ Ureterolithotomy \\
\hline & & Levofloxacin & $\begin{array}{l}\text { PCNL/ Nephrolithotomy, URLS/ Ureterolithotomy, Cystolitholapaxy, } \\
\text { Nephrectomy, TURP / RPP, Pyeloplasty, DJ Stenting, }\end{array}$ \\
\hline \multirow[t]{4}{*}{4.} & \multirow[t]{4}{*}{ Penicillins } & Flucloxacillin & Eversion of Sac, Wound Closure, I and D \\
\hline & & Ampicillin+Sulbactam & $\begin{array}{l}\text { PCNL/ Nephrolithotomy, URLS/ Ureterolithotomy, Cystolitholapaxy, } \\
\text { Nephrectomy, TURP/ RPP, TURBT, Pyeloplasty }\end{array}$ \\
\hline & & $\begin{array}{l}\text { Amoxycillin plus } \\
\text { Clavulanic acid }\end{array}$ & $I \& D$ \\
\hline & & $\begin{array}{l}\text { Piperacillin plus } \\
\text { Tazobactam }\end{array}$ & $\begin{array}{l}\text { Gastrectomy, Exploratory Laparotomy, Esophagotomy, Resection and } \\
\text { Anastomosis, Debridement }\end{array}$ \\
\hline 5. & Anti-anaerobic & Metronidazole & $\begin{array}{l}\text { Appendectomy, Cholecystectomy, Gastrectomy, Hemicolectomy, } \\
\text { Exploratory Laparotomy, Ileostomy Closure, Resection and Anastomosis, } \\
\text { Hemorrhoidectomy/ LIFT/ Sphincterotomy, Karydaky's Procedure, } \\
\text { Debridement, I \& D }\end{array}$ \\
\hline
\end{tabular}

Eighteen types of drugs from seven different antimicrobial groups were found to be used either alone or in combinations during the perioperative period. Third-generation cephalosporins were the most commonly prescribed drugs in our study. Ceftriaxone, cefixime, cefotaxime, cefuroxime and cefazolin were used from group cephalosporin whereas the penicillins used were piperacillin, ampicillin, amoxicillin in combination with tazobactam, sulbactam and clavulanic acid respectively. Amikacin and gentamycin were common aminoglycosides used in combination with metronidazole during post-operative period and followups. The pattern of the top five antimicrobials used in different types of surgery during the perioperative period is shown in Table 2.

Table 3. Antimicrobial prescription rate in in perioperative stages of sugery

\begin{tabular}{|c|c|c|c|c|} 
& $\begin{array}{c}\text { Gastro } \\
\text { surgery }\end{array}$ & $\begin{array}{c}\text { Uro } \\
\text { Surgery }\end{array}$ & Others & $\begin{array}{l}\text { P } \\
\text { value }\end{array}$ \\
\hline Preoperative & 0.30 & 0.04 & 0.25 & $>0.05$ \\
\hline Intraoperative & 1.36 & 1.29 & 1.39 & \\
\hline Post operative & 2.31 & 2.22 & 1.82 & \\
\hline
\end{tabular}

The preoperative antimicrobial prescription rate for gastrointestinal surgery, urosurgery and other surgeries were $0.30,0.04$ and 0.25 respectively. Similarly, the intraoperative antimicrobial prescription rate for gastrointestinal surgery, urosurgery and other surgeries were 1.36, 1.29 and 1.39 respectively whereas postoperatively the rates were 2.31 , 2.22 and 1.82 respectively (Table 3 .)

In terms of compliance of antibiotic administration, 179 cases $(80.1 \%)$ were in accordance with the National guidelines while 170 cases $(76.3 \%)$ were in accordance with the international guidelines. However, no significant association was present between antibiotic administration and the type of surgery for both National and International Guidelines as seen by chi-square test $(p=0.775$ and $p=0.670$ respectively) (Table 4).

\section{Discussion}

Prescribing prophylactic antibiotics before surgery is an effective factor in reducing the incidence of postoperative surgical wound infection. However, its appropriate usage in terms of the right dose, type of antibiotic, duration of administration and time interval between the antibiotic 
Table 4. Compliance with the timing of antibiotic administration based on National and International guidelines

\begin{tabular}{|l|l|l|l|l|}
\hline $\begin{array}{l}\text { Type of } \\
\text { surgery }\end{array}$ & $\begin{array}{l}\text { Compliance with } \\
\text { guidelines }\end{array}$ & \multicolumn{3}{|c|}{ P value } \\
\hline & National & International & National & International \\
\hline $\begin{array}{l}\text { General } \\
\text { surgery }\end{array}$ & $\begin{array}{l}143 \\
(79.8 \%)\end{array}$ & $\begin{array}{l}147 \\
(86.4 \%)\end{array}$ & 0.775 & 0.670 \\
\hline $\begin{array}{l}\text { Uro } \\
\text { Surgery }\end{array}$ & $\begin{array}{l}36 \\
(20.11 \%)\end{array}$ & $\begin{array}{l}23 \\
(13.5 \%)\end{array}$ & & \\
\hline Total & $\begin{array}{l}179 \\
(80.1 \%)\end{array}$ & $\begin{array}{ll}170 \\
(76.3 \%)\end{array}$ & \\
& & & \\
\hline
\end{tabular}

administration is necessary to acquire desired outcomes. ${ }^{10}$ This study included prescriptions of 223 patients, in which $54.7 \%, 32.7 \%$ and $12.6 \%$ were having diseases from the gastrointestinal system, genitourinary system and others (breast, vascular, plastic, etc.) respectively. These findings were similar to Sane et al who reported $64 \%$ of gastrointestinal cases and $24 \%$ of genitourinary cases. ${ }^{13,14}$ Our study showed the maximum number of patients from 51 to 60 years age groups whereas a study done by Patel KM et al showed the maximum number of patients from 20 to 50 years age group. The mean age of our patient was slightly higher than the findings of Patel KM et al and Alemkere G. ${ }^{15}$ ${ }^{16}$ The male to female ratio was $1.29: 1$ whereas it was $1.42: 1$, 1.53:1 and 1.50:1 in different studies conducted in Ethopia, India and Nepal respectively. ${ }^{13-15}$ The length of hospital stay was $3.23 \pm 2.14$ days which is lesser than the study done by Alemkere G (8 days) and Patel KM et al (7.44 4.82 days).

Appendicitis was the most common diagnosis followed by hernia which was similar to the findings of Alemkere $\mathrm{G}$ et $\mathrm{al}^{16}$ which reported appendicitis as the most common diagnosis followed by colorectal cases. ${ }^{16}$ Though the common diagnosis was urinary stone and related diseases the most common surgeries performed was found to be emergency appendectomy. Among the urinary stone disease, common disease were renal stone, pelvic-ureteric stone, ureteric stone and vesical stone for which various modalities of surgeries like PCNL, nephrolithotomy, URSL, ureterolithotomy, cystolitholapaxy and cystolithotomy were performed.

The postoperative antimicrobial prescription rate was found higher than pre and intraoperative antimicrobial prescription in our study which was similar to the study conducted by Alemkere $\mathrm{G}$ et al. ${ }^{16}$ The common injectable antimicrobial agent prescribed perioperatively was ceftriaxone followed by metronidazole. Similarly, most common oral antimicrobial used preoperatively was tablet ofloxacin and ciprofloxacin whereas postoperatively was tablet cefixime, ciprofloxacin and metronidazole respectively. The study done by Viola et al reported cefazolin and cefadroxil as the commonest antimicrobial used preoperatively and postoperatively respectively. ${ }^{18}$ Similarly, Murri et al reported cefazolin, beta-lactam/ beta-lactamase inhibitors, quinolones and carbapenem as the most commonly used antimicrobial agents perioperatively. ${ }^{19}$ The basis of antimicrobial prescription for prophylaxis and treatment was found to be empirical which was similar to study done in India, Ethopia and Italy. ${ }^{15,18,19}$ The maximum numbers of antimicrobials were used postoperatively as there might be a higher incidence of complications postoperatively which is similar to the findings of Alamrew et al. This study reported $83.7 \%$ cases where antimicrobials were used postoperatively. ${ }^{18}$

The degree of compliance with administration prophylactic antibiotics in the present study according to national guidelines was $80.1 \%$ and that according to international guideline was $76.3 \%$, respectively. The outcomes of our study also reported that national and international guidelines regarding perioperative usage of antibiotics are not significantly different and do not depend on the type of surgery. In the study of Akbari et al the rate of conformity of time, type, dose, duration and intervals of antibiotic administration according to national guidelines was equal to $88 \%$ which was much higher as compared to our study. ${ }^{20}$ On the other hand, in the study conducted in Australia, showed the compliance of $76.4 \%$ as per the guideline, which is not consistent with the current study. ${ }^{21}$ An ideal antimicrobial should be selected based on its pharmacokinetic profile, its toxicity, cost, mode of administration, drugs sensitivity pattern, bacteriological profile, hospital antimicrobial resistance pattern, clinical effectiveness and patients condition. ${ }^{22-25}$ Our study showed inappropriate antimicrobial use in the form of overuse of antimicrobials without appropriate indications during the postoperative period which may be due to false belief of surgeons that it provides better coverage against probable SSIs, inability to adhere to standard treatment guidelines, lack of regular surveys of antimicrobial uses and inadequate knowledge regarding antibiotic stewardship.

The use of antimicrobials for prophylaxis should be based on the possible benefits and risks. Discouraging the indiscriminate use of antimicrobials might delay or prevent the development of antimicrobials-resistant strains or serious hypersensitivity reactions. ${ }^{26-28}$ It is high time for every health care institution to regularly reassess antimicrobial prescription practices, conduct regular pharmacovigilance meetings within and outside of the department and consensus meetings with all stakeholders to formulate standard treatment guidelines and advocate strict antibiotic stewardship.

\section{Conclusion}

The study on antimicrobial prescription patterns during the perioperative period has a greater impact on patient outcome and prognosis. The commonly used antimicrobials in this study were third-generation cephalosporin followed by antianaerobes, penicillin combination, fluoroquinolones and aminoglycosides. This study also found a gap in compliance of antimicrobial prescription compared to national and international guidelines especially during the postoperative period of patient care.

Acknowledgement: I would like to acknowledge the patients and the staffs of Department of surgery, Shree Birendra Hospital for their patience and helping me out complete this study. 
References

1. Bass BL, Garbey M. A road map for computational surgery: challenges and opportunities. J Comput Surg. 2014;1(1):2.

2. Zhou C, Chen X, Wu L, Qu J. Distribution of drug-resistant bacteria and rational use of clinical antimicrobial agents. Exp Ther Med. 2016;11(6):222932.

3. Lambrini K, Kotsiftopoulos $\mathrm{CH}$, Papageorgiou M, Iliadis $\mathrm{CH}$, Monios A. The rational use of antibiotics medicine. J Healthc Commun. 2017;2(3):27.

4. Saini N, Saini V, Mehta PW. Misuse of antibiotics: a potential threat. IOSR J Dent Med Sci. 2014;13(7):6872.

5. Matsuda S, Ikawa F, Ohba H, Yoshiyama M, Hidaka T, Kurisu K, et al. Questionnaire Survey Regarding Prevention of Surgical Site Infection after Neurosurgery in Japan: Focus on Perioperative Management and Administration of Surgical Antibiotic Prophylaxis. Neurol Med Chir (Tokyo). 2019 Jun 15;59(6):197-203.

6. Dellinger EP. Prophylactic antibiotics: administration and timing before operation are more important than administration after operation. Clin Infect Dis. 2007;44(7):928-30.

7. Bratzler DW, Houck PM. Antimicrobial prophylaxis for surgery: an advisory statement from the national surgical infection prevention project. Clin Infect Dis. 2004;38(12):1706-15.

8. Satti MZ, Hamza M, Sajid Z, Asif O, Ahmed H, Zaidi SMJ et al. Compliance Rate of Surgical Antimicrobial Prophylaxis and its Association with Knowledge of Guidelines Among Surgical Residents in a Tertiary Care Public Hospital of a Developing Country. Cureus. 2019 May 29;11(5): e4776.

9. Kwak YG. Appropriate use of surgical antibiotics prophylaxis. J Korean Med Sci. 2019 May 6;34(17):e136.

10. Courtney L, Nankervis JM, James R, Rajkhowa A, Peel T, Thursky K. Surgical antimicrobial prophylaxis. Aust Prescr. 2017; 40(6):225-9.

11. World Health Organization. (2016)! Global Guidelines for the Prevention of Surgical Site Infection. World Health Organization. Available from: https://apps. who.int/iris/handle/10665/250680

12. National Antibiotic Treatment Guidelines-2014 (Technical Report). Ministry of Health and Population, Government of Nepal. 2014. Available from: https:// mohp.gov.np/downloads/National_Antibiotic Treatment_Guidelines.pdf

13. National list of essential medicines. Department of drug administration, Ministry of health, Government of Nepal. 5th revision. 2016. Available from: http:// apps.who.int/medicinedocs/documents/s23537en/ s23537en.pdf

14. Sane RM, Shahani SR, Kalyanshetti AA. Antibiotic prescription pattern in surgical wards of MGM Hospital, Kamothe. Int J Infect. 2018;5(1):e57914.

15. Patel KM, Jadav SD, Parmar AP, Trivedi H. Drug prescribing pattern in surgical wards of a tertiary care hospital in western part of India. International Journal of Basic and Clinical Pharmacology. 2018;7(8):158792.

16. Alemkere G. Antibiotic usage in surgical prophylaxis: A prospective observational study in the surgical ward of Nekemte referral hospital. PLoS One. 2018 Sep 13;13(9):e0203523.

17. Giri BR, Pant HP, Shankar PR, Sreeramareddy CT, Sen PK. Surgical site infection and antibiotics use pattern in a tertiary care hospital in Nepal. J Pak Med Assoc. 2008;58(3):148-50.

18. Alamrew K, Tadesse TA, Abiye AA, Shibeshi W. Surgical antimicrobial prophylaxis and incidence of surgical site infections at Ethiopian tertiarycare teaching hospital. Infect Dis (Aukl). 2019 Nov;12:1178633719892267.

19. Murri R, de Belvis AG, Fantoni M, Tanzariello M, Parente P, Marventano S, et al. Impact of antibiotic stewardship on perioperative antimicrobial prophylaxis. Int J Qual Health Care. 2016 Sep;28(4):502-7.

20. Afhami SH, Esmailpour BN, Boujar AN, Sayadi L. Antibiotic prophylaxis before surgeries. Iranian Journal of Surgery. 2011;19(3):28-32.

21. Bull AL, Russo PL, Friedman ND, Bennett NJ, Boardman CJ, Richards MJ. Compliance with surgical antibiotic prophylaxis reporting from a statewide surveillance programme in Victoria, Australia. J Hosp Infect. 2006 Jun;63(2):140-7.

22. Viola GM, Rolston KV, Butler C, Selber J, Reece G, Clemens $\mathrm{M}$ et al. Evaluation of current perioperative antimicrobial regimens for the prevention of surgical site infections in breast implant-based reconstructive surgeries. Plast Reconstr Surg Glob Open. 2019 Jul;7(7):e2342.

23. Eriksen HM, Chugulu S, Kondo S, Lingaas E. Surgicalsite infection at Kilimanjaro Christian medical centre. J Hosp Infect. 2003 Sep;55(1):14-20.

24. Mwita JC, Souda S, Magafu MGMD, Massele A, Godman B, Mwandri M. Prophylactic antibiotics to prevent surgical site infections in Botswana: findings and implications. Hosp pract (1995). 2018 Aug;46(3):97-102.

25. Fukatsu K, Saito H, Matsuda T, Ikeda S, Furukawa S, Muto T. Influences of type and duration of antimicrobial prophylaxis on an outbreak of methicillin-resistant staphylococcus aureus and on the incidence of wound infection. Arch Surg. 1997 Dec;132(12):1320-5.

26. Dancer SJ. The problem with cephalosporins. J Antimicrob Chemother. 2001; 48(4):463-78.

27. Raut B, Khadka A, Borah RN. Prescription Patterns of Antimicrobial Drugs in Hospitalized Patients in Tertiary Care Hospital of Kathmandu. Medical Journal of Shree Birendra Hospital. 2016 Jul 5;15(1):52-60.

28. Eskicioglu C, Gagliardi AR, Fenech DS, Forbes SS, McKenzie M, McLeod RS, et al. Surgical site infection prevention: a survey to identify the gap between evidence and practice in University of Toronto teaching hospitals. Can J Surg. 2012 Aug;55(4):233-8. 